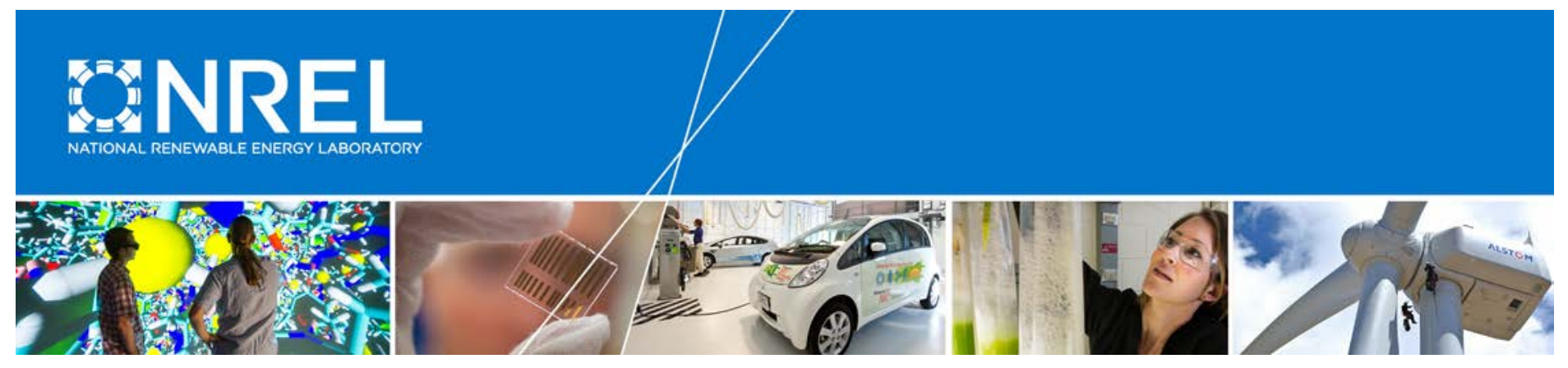

\title{
Hydropower Modeling Challenges
}

Brady Stoll, Juan Andrade, Stuart Cohen, Greg Brinkman, and Carlo Brancucci Martinez-Anido National Renewable Energy Laboratory

NREL is a national laboratory of the U.S. Department of Energy Office of Energy Efficiency \& Renewable Energy Operated by the Alliance for Sustainable Energy, LLC

This report is available at no cost from the National Renewable Energy Laboratory (NREL) at www.nrel.gov/publications.

Technical Report

NREL/TP-5D00-68231

April 2017

Contract No. DE-AC36-08G028308 


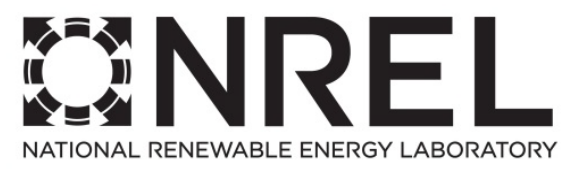

\section{Hydropower Modeling Challenges}

Brady Stoll, Juan Andrade, Stuart Cohen, Greg Brinkman, and Carlo Brancucci Martinez-Anido National Renewable Energy Laboratory

Prepared under Task No. WFGX.1040

NREL is a national laboratory of the U.S. Department of Energy Office of Energy Efficiency \& Renewable Energy Operated by the Alliance for Sustainable Energy, LLC

This report is available at no cost from the National Renewable Energy Laboratory (NREL) at www.nrel.gov/publications.

National Renewable Energy Laboratory 15013 Denver West Parkway Golden, CO 80401 303-275-3000 • www.nrel.gov

\section{Technical Report}

NREL/TP-5D00-68231

April 2017

Contract No. DE-AC36-08G028308 


\section{NOTICE}

This report was prepared as an account of work sponsored by an agency of the United States government. Neither the United States government nor any agency thereof, nor any of their employees, makes any warranty, express or implied, or assumes any legal liability or responsibility for the accuracy, completeness, or usefulness of any information, apparatus, product, or process disclosed, or represents that its use would not infringe privately owned rights. Reference herein to any specific commercial product, process, or service by trade name, trademark, manufacturer, or otherwise does not necessarily constitute or imply its endorsement, recommendation, or favoring by the United States government or any agency thereof. The views and opinions of authors expressed herein do not necessarily state or reflect those of the United States government or any agency thereof.

This report is available at no cost from the National Renewable Energy Laboratory (NREL) at www.nrel.gov/publications.

Available electronically at SciTech Connect http:/www.osti.gov/scitech

Available for a processing fee to U.S. Department of Energy and its contractors, in paper, from:

U.S. Department of Energy

Office of Scientific and Technical Information

P.O. Box 62

Oak Ridge, TN 37831-0062

OSTI http://www.osti.gov

Phone: 865.576.8401

Fax: 865.576.5728

Email: reports@osti.gov

Available for sale to the public, in paper, from:

U.S. Department of Commerce

National Technical Information Service

5301 Shawnee Road

Alexandria, VA 22312

NTIS http://www.ntis.gov

Phone: 800.553 .6847 or 703.605 .6000

Fax: 703.605.6900

Email: orders@ntis.gov 


\section{Acknowledgments}

The National Renewable Energy Laboratory team thanks the U.S. Bureau of Reclamation for the opportunity to develop this report. In particular, the team is grateful to James Anders, Clark Bishop, Erin Foraker, Todd Gaston, and Michael Pulskamp for their guidance and generous assistance throughout the development of this project. 


\section{List of Acronyms}

\section{CEM}

GW

$\mathrm{kW}$

PCM

ReEDS

RPM

TWh capacity expansion model

gigawatt

kilowatt

production cost model

Regional Energy Deployment System

Resource Planning Model

terawatt-hours 


\section{Executive Summary}

Hydropower facilities are important assets for the electric power sector and represent a key source of flexibility for electric grids with high penetrations of variable generation. As variable renewable generation sources expand, understanding the capabilities and limitations of the flexibility from hydropower resources is important for grid planning. Appropriately modeling these resources, however, is difficult because of the wide variety of constraints these plants face that other generators do not. These constraints can be broadly categorized as environmental, operational, and regulatory. This report highlights several key issues incorporating these constraints when modeling hydropower operations in production cost and capacity expansion models. Many of these challenges involve a lack of data to adequately represent the constraints or issues of model complexity and run time. We present several potential methods for improving the accuracy of hydropower representation in these models to allow for a better understanding of hydropower's capabilities on the electric grid. 


\section{Table of Contents}

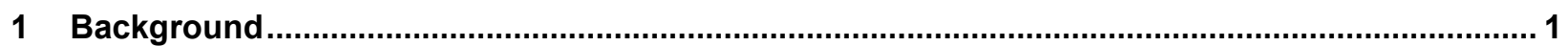

1.1 Hydropower Technologies and Water Resources .......................................................... 2

1.2 Power System Models ..................................................................................................... 4

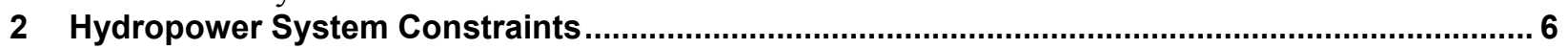

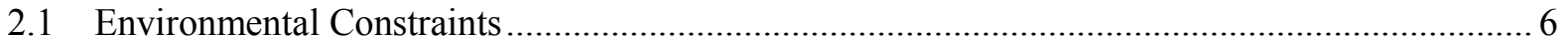

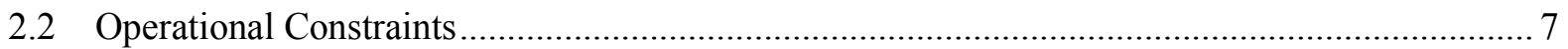

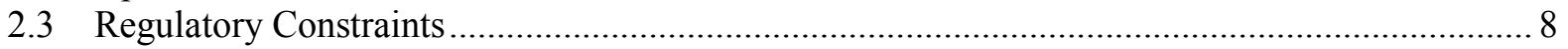

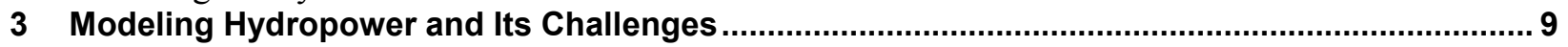

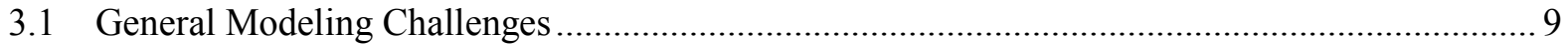

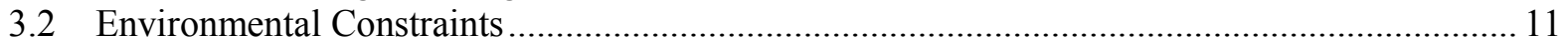

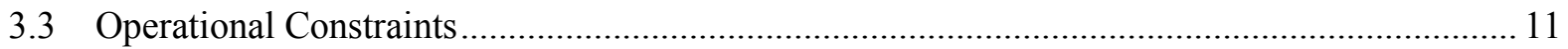

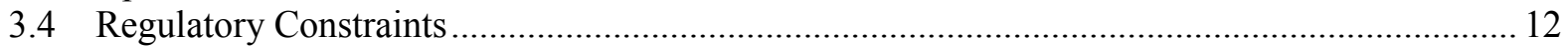

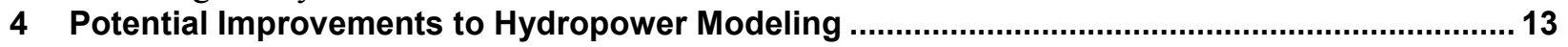

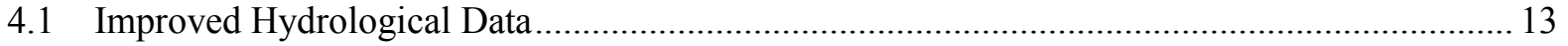

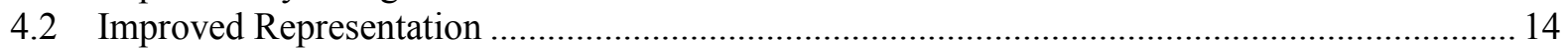

4.3 Link Power System Model and Water System Model ........................................................ 15

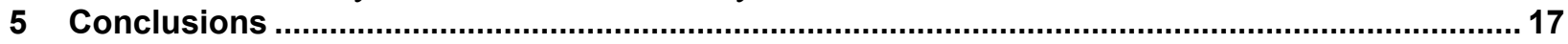

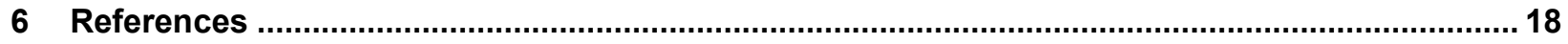




\section{List of Tables}

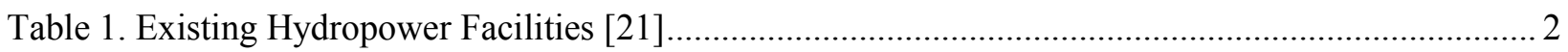

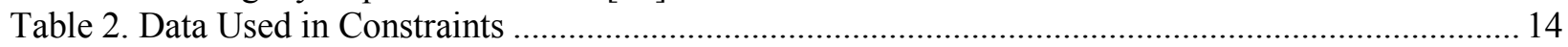




\section{Background}

Hydropower is used worldwide to provide relatively low-marginal-cost, low-emission electricity. Hydropower facilities with reservoirs are also typically some of the most flexible types of generators in the power sector. This flexibility is becoming increasingly important as variable generation sources such as wind and solar become more prevalent. Electricity generation from renewable energy sources, excluding hydropower, has increased sevenfold during the past 10 years [1], and it is expected to continue to increase, with variable renewable sources providing up to $30 \%$ of global electricity by 2040 [2]. These increases in variable renewable generation have led to a rising interest and concern for power systems models to adequately represent how these resources will impact the reliability of the electric power grid. Recent studies [3]-[7] show an increasing desire to understand and better plan for the future challenges associated with growth in variable renewable energy resources and the need to integrate these resources into the power system. A particular challenge for variable generation technologies, specifically wind and solar photovoltaic, is the inability to dispatch energy on demand because of their weather dependence. This variability and their uncertainty leads to a need for flexibility from the remainder of generators to balance load and demand across the grid [8]-[10].

Flexibility is a key resource for the electric grid; in particular, it enables balancing demand with generation despite normal and unexpected variability in load or resource availability and from forecast errors. Flexibility can take several forms, including the ability to ramp quickly and the provision of ancillary services. Ancillary services are particular grid products designed to help balance load. They typically consist of a contingency reserve to mitigate large losses in generation or transmission and a regulation reserve to help balance small fluctuations in load or variable generation.

In general, large hydropower facilities have the capability to provide a significant amount of flexibility to the electric grid because of their fast ramping capabilities and innate storage in the reservoirs behind large dams [11]. Several studies have directly analyzed the ability of hydropower to address the challenges of variable generation [12]-[14]; however, hydropower facilities are often also subject to numerous constraints that limit their generation potential in ways that are not seen in other power plants. These constraints can generally be categorized as environmental, operational, and regulatory. When performing studies on the power system, hydropower modeling should incorporate these constraints to most accurately represent the capabilities of these facilities to potentially facilitate the integration of variable renewable energy resources into the power system [15]-[17]; however, most models do not comprehensively represent the constraints on hydropower operations for various reasons, including a lack of computational resources, the modeling time required with increasingly complex models, or a lack of data to properly account for hydrological considerations. This can lead to inaccurate estimates of the ability of hydropower facilities to provide flexibility. Particularly as concerns regarding climate change and long-term droughts increase [18], [19], correctly modeling hydropower will become increasingly important to fully understand the needs and limitations of the electric grid [16], [20].

This paper provides a review of hydropower operations and the constraints on its ability to provide flexibility as well as a review of current modeling practices to represent hydropower in 
power system models. We comment on the degree to which these models can be improved to more accurately represent hydropower facilities in the face of real-world constraints.

\subsection{Hydropower Technologies and Water Resources}

Hydropower is used around the world as a power resource. China leads in terms of installed capacity, followed by Brazil and the United States [21]; however, Norway and many countries in Africa provide more than $80 \%$ of their electricity from hydroelectric power [21]. Additionally, some regions, such as the Pacific Northwest in the United States, can have much higher penetrations of hydropower than the countrywide average. It is particularly important to adequately represent hydropower constraints when analyzing countries or regions with high shares of hydropower electricity generation. Table 1 shows the amount of electricity produced by hydropower, both in terms of terawatt-hours (TWh) and as a percentage of generation for the countries that have the highest installed capacity of hydropower.

Table 1. Existing Hydropower Facilities [21]

\begin{tabular}{l|lll} 
& $\begin{array}{l}\text { Capacity } \\
\text { (GW) }\end{array}$ & $\begin{array}{l}\text { Generation } \\
\text { (TWh) }\end{array}$ & $\begin{array}{l}\text { Percentage of } \\
\text { Total Generation } \\
(\%)\end{array}$ \\
\hline China & 249.0 & 856.4 & 18.0 \\
Brazil & 84.3 & 411.2 & 76.5 \\
United States & 78.7 & 276.2 & 6.8 \\
Canada & 75.4 & 376.7 & 61.1 \\
Russia & 47.4 & 164.4 & 16.2 \\
India & 42.8 & 124.6 & 11.8 \\
Norway & 28.6 & 140.5 & 97.1 \\
Japan & 22.2 & 74.7 & 7.7 \\
Turkey & 19.6 & 57.3 & 25.1 \\
France & 18.4 & 58.1 & 10.9 \\
World & $\mathbf{9 7 9 . 1}$ & $\mathbf{3 , 6 4 6 . 1}$ & $\mathbf{1 6 . 9}$
\end{tabular}

Worldwide, the development of new hydropower plants has been facing barriers such as increased environmental regulations, social opposition, and costs [22]. The major areas for new hydropower developments are in Africa, Asia, and South America [23]. In the United States, a study has identified the potential for new stream-reach development to provide up to 347.3 $\mathrm{TWh} /$ year, approximately $128 \%$ of the average net annual generation from existing hydropower plants from the years 2002-2011 [24]. Additionally, hydropower turbines could be placed in the discharge of non-powered dams and non-powered conduits [25]. Note that this type of hydropower facility could be limited to reproducing the historic river flows and thus may have limited flexibility.

Water use is an important aspect of the electric power system as a whole; it accounts for more than $45 \%$ of all water withdrawn in the United States [26], in large part for the cooling needs of conventional electricity generators. Water is additionally used as a fuel source for hydropower. 
Water systems are large networks connecting many different participants, including dams and reservoirs, river basins, wildlife, and downstream agricultural users. This connectivity and the need to preserve water for downstream users directly affects the amounts of power and ancillary services a facility can provide. Although these considerations are important for all generation facilities that use water, hydropower is unique in that water is the primary fuel for electricity generation. Hydropower's inextricable link between water and power generation amplifies the need for prudent water system management compared to non-hydropower generation facilities.

The water regime in which a hydropower facility is located plays a significant role in determining what constraints are imposed on the facility and to what extent these constraints will limit power generation. Water regime is defined by seasonal patterns of water availability because of precipitation, evaporation, drainage, and other characteristics, which all depend on the geography and weather characteristics of a location. These regimes need to be considered to strategically use the water stored in reservoirs and to best understand the yearly variations in water availability. For example, a river basin fed by glacial melt will be much more predictable than a river basin fed solely through precipitation.

The patterns and uncertainty associated with water regimes, and therefore water inflows into reservoirs, have an important impact on the operation of hydropower generation and reservoir storage. The inflows define the operational bounds of hydropower and create limits on the amount of energy and ancillary services that can be produced and on the ability of these facilities to modulate flow rates and power output. Inflows include precipitation, surface runoff, and snowmelt, and ice melt. The actual variability of these flows from one year to another can be high, leading to different operational regimes for hydropower facilities from one year to another.

Weather, and in particular precipitation and runoff, is of great relevance for hydropower generation [27]. The amount of precipitation directly impacts the water available for use in hydropower facilities, and conditions such as net radiation that is higher than average or dry conditions can impact the rates of evaporation in reservoirs [28]. Although hydrological systems have typical patterns of wet and dry seasons that are relatively predictable, these patterns are not guaranteed and can change significantly from one year to another. Climate change impacts can also greatly affect historic weather patterns, leading to both increased and decreased hydropower generation in different regions [27].

Water quality is another important aspect of the water resource, and its regulation shapes some of the environmental constraints for hydropower facilities [15]. Water quality describes the condition of the water-including its chemical, physical, and biological characteristics - usually with respect to its suitability for a particular purpose. Examples of regulated variables include temperature, $\mathrm{pH}$, dissolved oxygen, and turbidity. Changes in these properties could produce economic impacts in certain activities (e.g., fishing, recreation), environmental damages, and harm to aquatic species. An example of this is the thermal stratification of water stored in reservoirs. Water in a reservoir will stratify into different layers according to temperature, leading to a warmer top layer and colder bottom layer. This stratification can also lead to differences in dissolved oxygen in the layers, with more oxygen at the surface and less oxygen in the bottom layers. Additionally, spilling water from dams can impact the amount of dissolved gasses in the water. 
Hydropower facilities cover a broad range of technologies and operational regimes. The size of these facilities can vary greatly, from those with electricity generation capacity as small as kilowatts $(\mathrm{kW})$ to as large as gigawatts $(\mathrm{GW})$; however, within this range there are technologies that have similar considerations for their operation. These are grouped into three broad categories: (1) reservoir hydropower plants; (2) pumped storage facilities; and (3) run-of-river hydropower plants.

Reservoir hydropower facilities are characterized by the presence of a large reservoir that can store water for later use, allowing the facility to regulate its output depending on constraints regarding reservoir levels and downstream impacts of water release. Important considerations for these types of hydropower facilities include the surface elevation of the reservoir - particularly to control flooding, limit potential temperature stratification in the reservoir, and maintain water levels for recreational uses. Additionally, downstream water users may require a certain amount of water to be released for irrigation, municipal and industrial purposes, and to maintain stable habitats in the lower river environment.

Pumped storage is a variant of a reservoir power plant that allows the water to be returned from the discharge into the reservoir via a pump, or it contains a second reservoir at a higher elevation into which water may be pumped. This allows such facilities to be operated as storage devices, shifting load from periods of high demand to periods of low demand, which also enables greater flexibility for the system. Environmental considerations for pumped hydropower facilities are similar to those for reservoir hydropower facilities because both facilities can modulate their output.

Run-of-river hydropower generators exist alongside rivers and do not contain a large reservoir to store or regulate the flow of the adjacent river. Sometimes these facilities have a small storing capacity that can be used to modify the generation profile to a small degree according to system load or electricity prices; however, typically they generate electricity according to the water flow. An intake of water upstream from the power plant transports water to the turbine through the penstock before returning to the river downstream. These types of facilities have requirements on acceptable bounds for the water quality and temperature, and they are limited by the flow of the river in which they are located.

The provision of electricity generation as a second-order interest - following environmental, operational, and regulatory constraints - restricts the degree of flexibility that these facilities can provide. These constraints will be discussed in greater detail in Section 0.

\subsection{Power System Models}

Several types of models have been used to analyze the power system, each with a different focus. These include very short-term models that analyze grid reliability over a second or a fraction of a second, production cost models that operate on minutes to hours and focus on the operational aspects of the power sector and its ability to provide electricity to all demands, and long-term capacity expansion models that have a timescale of years and consider the future of the power sector for planning purposes [29]. We focus here on production cost models (PCMs) and capacity expansion models (CEMs) and their representations of hydropower. 
PCMs — such as PLEXOS [30], PROMOD [31], and MAPS [32]—focus on power system simulation over short time resolutions (e.g., 5 minutes to hourly). They can include uncertainty from the variations in load as well as the availability of power from variable generation (wind and solar). The decision variables considered in PCMs include the operation status of existing generation units and the amount of energy and reserves produced by existing generators. These models are concerned with balancing the load and generation of an existing system and identifying times of potential strain seen through curtailment, unserved energy, and unserved reserves. Hydropower generation is typically co-scheduled with thermal generation, and PCMs may have the ability to model stochastic distributions of inputs, such as inflows. Hydropower is frequently represented as a generator linked to a reservoir with constraints on the amount of energy that must be provided during a given period, often a month. The reservoir surface elevation is also tracked and required to be between allowable bounds. Pumped hydropower facilities can also be represented with the ability to store energy in the reservoir.

CEMs - including the Regional Energy Deployment System (ReEDS) [33], Resource Planning Model (RPM) [34], and AURORAxmp [35] - focus on medium- and long-term investment decisions. They can inform the type of technology and capacity to install given a variety of assumptions about future costs and conditions. Although they focus on investment decisions, these models typically also model the operation of the power system in question, though at a more coarse temporal resolution than PCMs. Capacity expansion models consider the operational statuses of generators, the costs of installing new generators of various types, and the operational statuses of these new generators. Hydropower is frequently modeled based on long- and medium-term water capacity constraints in these models.

Watershed models typically focus on water systems rather than the broader power system. These types of models directly model environmental impacts, flow rates, and water availability, as well as the impact of operational choices from one facility on all downstream facilities. They also simulate and optimize the operation of hydropower generation in the realm of water systems and power systems and their constraints. Examples of watershed models include RiverWare [36] and the Water Use Optimization Toolset/Conventional Hydropower Energy and Environmental Systems Tool [37]. RiverWare in particular models an entire river system, including all reservoirs, waterways and their associated hydrology, water quality, water rights, and accounting. Additionally, it can be used to optimize the operation of hydropower facilities.

PCMs and CEMs are mainly concerned with correctly representing constraints related to the power sector and generator operational capabilities. Although they can perform basic modeling of water systems, this functionality is more limited than that of watershed models. Similarly, watershed models focus on correctly representing water systems and do so to a high degree of fidelity, but they have only a basic representation of the electric power system and its interactions. Ideally, a tool used to analyze the power system would be able to account for both power and river system considerations simultaneously. Although this is technically feasible, many of the necessary river system constraints have not been implemented in PCMs or CEMs because of the data and run-time challenges presented in running these tools simultaneously [17]. 


\section{Hydropower System Constraints}

Hydropower facilities have a wide range of constraints on their operation because of their participation in both electric power systems and water systems, with each placing a set of requirements on hydropower facilities. As electricity generators, hydropower facilities have constraints similar to those of traditional power generators, including the maximum capacity of the system, maintenance requirements, ability to provide reserves, and contracts on power provision. As hydrological reservoirs, hydropower facilities are also faced with environmental and regulatory constraints, including spillage limitations, reservoir level constraints, seasonal water releases, water quality concerns, and downstream impacts. This section examines these constraints in more detail.

\subsection{Environmental Constraints}

Hydropower facilities have a direct connection to local water systems, impacting the characteristics of naturally flowing water, including its temperature, dissolved gas content, and flow rate [11]. These impacts occur predominantly from the presence of dams [38]. If not well managed, these facilities can have negative impacts on local and downstream environments; thus, many regulations on hydropower facilities have been implemented that are not directly related to power production, and they may not be fully captured in electricity models.

Environmental considerations for dams include impacts on aquatic species and erosion [39]. These issues place constraints on hydropower operation, including limitations on the minimum amount of water that must be released, reservoir level restrictions, and flow rate requirements [40].

Many concerns for hydropower operation are related to the interconnected nature of water systems, such that a hydropower facility must take into consideration the impacts of water releases and their timing on all downstream participants, including aquatic species and their food chains [41], and other water users such as farms and cities. Aquatic species have specific environments in which they are able to grow and prosper; hydropower facilities can negatively impact both the availability of water and the water quality in these environments [11], [39]. Additionally, farms and cities require certain quantities of water for irrigation and drinking. Environmental flow is established from both of these considerations, creating a minimum water flow that must be released to best serve downstream users or to best mimic natural flows [15], [41]. These flows typically limit the amount of water a dam may release, and they can vary throughout the year according to prevailing conditions and hydrological cycles.

Additionally, storing water in reservoirs for prolonged periods can produce thermal stratification of the water in the reservoir, causing the water at the top to be significantly warmer than the water at the bottom. Releasing cooler water could lower the temperature of the river at the outlet, potentially moving the river out of acceptable temperature ranges for some species. This issue also contributes to limitations on the timing of releasing water from a reservoir.

Reservoir limitations are implemented to ensure aquatic species have appropriate habitats and to support the multiuse functionality of reservoirs. For example, Lake Mohave in the Colorado River basin contains endangered razorback suckers that require certain reservoir levels during spawning season [42]. 
Water release flow rates from hydropower facilities may be required to maintain in-stream flows, limit the variability of downstream flows, and reproduce conditions similar to natural flow [41]. This can lead to constraints on the ramping abilities of hydropower generators and on total release volume [40]. Reservoirs may also spill water if water must be released when power is not needed. This is similar to the curtailment of wind and solar power when these resources cannot be integrated into the electric grid. Spilling water from a reservoir affects the water quality downstream by increasing the total gas dissolution in the water [43].

Finally, climate change impacts are expected to increase constraints on hydropower operation. Changes to the global climate could impact runoff patterns [44], lead to regional increases and decreases in water availability [27], and change river levels and temperature [20]. All of these impacts could make environmental constraints on hydropower more binding in the future.

\subsection{Operational Constraints}

Hydropower generators also face many of the same operational constraints as thermal generators, including ramping and minimum generation levels; however, hydropower generators are also limited by constraints particularly related to water. These constraints limit the operation of hydropower by the (1) amount of energy that can be produced, (2) maximum and minimum amount of power that can be produced, and (3) upward and downward ramping rates. Although hydropower is among the most flexible dispatchable resources, these constraints limit the ability of hydropower facilities to absorb the variability and uncertainty of variable energy sources [45].

Other operational considerations for hydropower include participation in electricity markets and the requirements therein. Hydropower facilities can participate in both the energy and ancillary service markets of the electric power system. Participation in these markets and the degree to which a facility can participate is impacted by both the available energy of the facility and any contracts to power that have been made. Additionally, participation in these markets requires following any commitment and dispatch schedules created by those markets.

The major operational constraints for hydropower are related to equipment capabilities, such as the minimum and maximum power able to be provided and maintenance requirements. Some turbine types have a minimum amount of power that must be produced if the turbine is to be operated as well as a maximum power capacity based on the rating of the turbine. Additionally, maintenance requirements limit the availability of turbines during periods of planned or forced outages of the facility. Turbines also have ranges of ideal operation, operation outside of which increases wear and tear, shortens the lifetime of equipment, and can negatively impact performance [46]. Although it is not a strict requirement, operation within these rough zones is strongly discouraged by operators.

Hydropower operations are at the mercy of ever-changing hydrological conditions. Reservoirs are impacted by water inflows - which may include natural inflows as well as the discharge of upstream hydropower generation or pumping units - and outflows - which include losses from evaporation and seepage. The available energy in a reservoir is constrained by the amount of water in the reservoir, and the maximum power that can be produced depends on the available water head. Both of these variables are impacted by the changing hydrological conditions surrounding a reservoir. 
Many reservoirs must also maintain a buffer to limit potential flooding, and they must account for sedimentation within the reservoir that may reduce the available storage capacity [19], [38]. Both of these factors limit the amount of energy able to be provided from a reservoir at a given time through their limits on the reservoir's storage capacity.

\subsection{Regulatory Constraints}

Regulations and agreements on water use often dictate the output and storage of a given hydropower facility. These include water rights, use of the water, flood control, and power regulations. Negotiations among several parties - which may include government agencies, private entities, or even countries - specify water releases in terms of total water flow during a certain time period, usually for a given month [40]. These regulations and release terms determine the operation of hydropower facilities from one year to another.

The right to store and divert water from rivers and lakes for beneficial use is controlled by a framework of water laws. These rights were originally intended for farming, irrigation, mining, municipal, and industrial uses. In the eastern United States, historically water has been plentiful, and riparian rights were established, which is an allocation of water among those who possess land along the water's path. In the western United States, water scarcity has led to the generalized adoption of the prior appropriation doctrine. The doctrine of prior appropriation is based on a first-come, first-served basis [47]. These laws place bounds on the amount of water that can, or must be, released in different seasons. Different regimes of water laws lead to very different legal environments for hydropower facilities. Accounting for these regulations is important when modeling hydropower operations.

The ownership and intended uses of a hydropower facility can impact the facility's operation by imposing objectives that may not be aligned with electricity market price signals. For example, many federal hydropower facilities have reservoirs that are multipurpose and may be used as recreational areas or habitats for protected species. Constraints on reservoirs related to recreational use are associated with particular surface elevation targets at certain times of the year. Similarly, the recreational use of rivers is an economic activity directly affected by the variations of in-stream flows, which places limits on water releases from dams, and it also potentially limits the rate of change of these releases. Reservoirs are also typically used for flood control of the downstream areas. Flood control operations require a certain amount of unutilized reservoir volume - which may vary throughout the year - to be available in case of rapid increases in water inflow.

Finally, power purchase agreements may be in place for hydropower facilities. These agreements require a certain amount of energy to be provided by a facility at a fixed price. Such agreements add additional constraints to hydropower operation based on contractual requirements to provide specified quantities of power regardless of economic and market conditions. 


\section{Modeling Hydropower and Its Challenges}

Modeling hydropower constraints accurately requires accounting for the wide variety of requirements for water flow, reservoir characteristics, and generation abilities described above. These constraints are typically not fully represented in power system models, which instead focus on generation and transmission requirements. Frequently, models will simply represent hydropower with its historical operational patterns [48]. Particularly when evaluating a changing mix of generation capacity to include more variable generation, it is important to more accurately model the actual production capabilities of hydropower rather than previous operational profiles. Important challenges related to modeling hydropower constraints include developing methods to represent the constraints within a power system model and ensuring that the proper hierarchy is assigned to each constraint for the specific hydropower facility.

\subsection{General Modeling Challenges}

Several challenges are associated with translating the requirements facing hydropower facilities into modeling constraints and how to appropriately represent the variety of constraints facing these facilities. These range from the need to represent some requirements in a simplified manner to the ability to accurately and simultaneously represent many timescales.

Hydropower operations are subject to constraints of different nature, some of which may be in conflict at times. Some constraints, such as the maximum operational capabilities of a generator, may not be violated; these are called hard constraints. On the other hand, respecting some constraints is preferred, or even strongly preferred, but not required; these are called soft constraints. An example of a soft constraint is the optimal operating range of turbines; operation outside of that range may not be profitable or desired, but it is possible.

Soft constraints can be modeled by incorporating a penalty cost associated with the violation. Depending on the constraint and the ability to violate that constraint, the penalty in the model can be very steep, such that it will be violated only in extreme conditions; or it may be fairly small if the constraint is relatively loose and represents a preferred operating condition rather than a strict limit. Setting these penalty costs to accurately represent the ability of constraints to be violated may be a challenge [43]. The penalty costs for soft constraints provide a relative order in which these constraints will be violated; for related constraints, this may allow one constraint to be violated to avoid violating another. Note that operators of hydropower plants fulfill soft constraints based on priority, which may include risk aversion, uncertainty in the quantification of constraint violation outcomes, and impacts of the violation. Prioritizing soft constraints imposes the need to deal with the trade-offs between violating a higher priority constraint or several lower priority constraints.

Another modeling challenge includes the operation of hydropower on different timescales-long term, medium term, and short term. Requirements with short timescales are concerned with the assurance of feasible operation of the electric and water systems in time periods of minutes, hours, and days; they do not consider, for example, how much water needs to be stored to fulfill future water constraints. Medium-term constraints are concerned with reservoirs that can store water for weeks or several months. Long-term constraints consider timeframes from years to multiple years, including changing hydrological cycles throughout a year or even climatic changes through decades. One of the main outcomes of medium- and long-term planning 
approaches is that they can give economic signals for water use at the end of the short-term period. This information can be expressed as a set of reservoir water volumes or a set of future cost functions for each reservoir. Future cost functions provide approximations for the future value of water, allowing models with short timescales to appropriately value longer-term requirements; however, these are approximations of future value and may not fully represent long-term constraints and the true flexibility of these constraints.

Correctly formulating soft constraints requires understanding the consequences of their violation during different timescales. Constraints vary from annual and monthly water delivery targets to instantaneous turbine operation conditions. PCMs and CEMs, which optimize the power market a single time step at a time, can only differentiate the violation of a month-long constraint or an instantaneous constraint by their penalty cost to the model during each time step. Correctly accounting for these temporal differences in the penalty function for a soft constraint ensures that the priority order - and the likelihood of a violation - for the constraints is met.

Another difficulty in formulating constraints is the time horizon modeled. The time horizon refers to the full length of the model simulation, which can vary from a single week to a year for PCMs to several decades for CEMs. This is particularly challenging for CEMs, which by necessity must use a longer time step or potentially model only several hours out of each year. The time step used in a model refers to the length of time in a particular interval. This is frequently 5 minutes or 1 hour for PCMs and may be 1 hour or more in CEMs. These models attempt to adequately represent the conditions within each modeled interval, and the models choose intervals to best represent constrained periods within a year; however, simplifications must be made to capture the most relevant aspects of operation. Even PCMs, which may model the power system at 5-minute time steps, do not fully capture the flexibility of hydropower systems at shorter timescales, at which hydropower's flexibility can be very valuable to grid operators. Additionally, the assumptions of PCMs about current time steps and their impact on future time steps, such as the future value of water, may over- or under-constrain hydropower operations.

It is difficult to model uncertainty in PCMs because of increased run times when running multiple years of simulations. Both CEMs and PCMs also typically capture only the weather of a single year, which may or may not be representative of hydropower conditions, particularly future hydropower conditions. Modeling more years to capture a wider variety of hydrological conditions can drastically increase run times. Although stochastic variables - such as changing hydrologic conditions - may be represented, both the additional run times required and acquiring data for these analyses make stochastic modeling difficult and in some cases unrealistic. As such, constraints that may have a large degree of uncertainty, such as input to a river or reservoir from precipitation, are typically modeled as deterministic parameters and variables.

Model complexity increases as additional constraints are considered, which can impact both the time it takes a model to solve and the ability of a model to find an optimal solution. Some constraints may vary by season or may be unique to particular hydropower facilities. Adding these additional constraints to a model will increase the model's complexity. Incorporating cascading hydropower, whereby the output of an upstream facility impacts a downstream facility, could further add to this complexity; however, accurately representing these facilities requires such constraints to be included. 
Implicit in many of the above challenges is run-time requirements. Adding additional constraints, and therefore complexity, to a model will inherently increase run time. A trade-off exists between accurate representation and the ability to fully simulate constraints within reasonable amounts of time. The difficulty of modeling a power system and all hydropower constraints may increase when incorporating more hydropower plants, in particular if the stochasticity of water inflows must be represented. In some cases, limitations in execution time make it infeasible to adopt a certain level of representation detail. For example, in a small hydrothermal power system, it makes sense to represent all thermal and hydropower plants in great detail; however, the same degree of representation for the Western Interconnection in the United States would be prohibitively slow (and require data that are difficult to acquire).

\subsection{Environmental Constraints}

One of the greatest hurdles for correctly representing environmental constraints is the absence of data. In most cases, enough data are not available to adequately model these constraints. These include data on specific plants to fully represent the different capabilities of individual facilities instead of groups of facilities, data on all aspects of facilities including reservoir levels and generator outputs, and data covering a temporal range that is large enough to capture all likely hydrological conditions.

Additionally, the evaluation of some constraints could be very computationally intensive or could add significant complexity to the model. Frequently these constraints are mapped to proxy variables already present in the models, such as water flows [43]. These constraints are summarized based on their impact on water availability, which is translated into specific limitations on the maximum or minimum amount of water that may be used during a given time. For example, temperature control of outflows into a river can be modeled by limiting the generation from the reservoir of a hydropower plant. Although the proxy does not correspond exactly to the actual variable, it can simplify the model by reducing the number of variables and equations that must be represented, allowing these constraints to be represented to some degree in the model; however, correctly creating the mappings between actual constraints and proxy variables can be challenging.

Valuating environmental constraints is difficult for power system models [43]. Energy provision has a direct economic value in the form of payments received and costs paid; however, environmental constraints do not have a direct monetary value, so they rely on proxy valuations. In particular for optimization models, these values can have a direct impact on the degree to which these constraints are violated and the order in which they are violated.

\subsection{Operational Constraints}

Operational constraints, particularly those common to all types of power generation facilities, are modeled to a high degree of accuracy by both PCMs and CEMs because these models focus on power generation. In particular, turbine and pumping efficiencies are able to be represented separately for different plants, and they can be represented as a function of generator output if so desired. Maintenance of facilities is also well represented. These models typically allow for both scheduled and forced outages within the model. The former are optimized within the model, and the latter are randomly assigned. This allows for reasonable estimations of the availability of hydropower facilities throughout the year. 
Both PCMs and CEMs are capable of modeling a hydropower reservoir and its changing levels. This is typically done by accounting for the known inflows and outflows of the reservoir, which can be tracked within the model; however, usually PCMs and CEMs do not have the same degree of information concerning these inflows and outflows as do watershed models, and usually they do not account for the connectivity of water resources. Within these models, inflows are frequently accounted for as fixed quantities that are known beforehand. Outflows are accounted for through the use of water to generate power and any spilling caused by curtailment of the facilities. These models do not typically represent the impacts of variations in output on downstream generators; and they may not account for smaller outflows, such as evaporation, at a detailed level.

A particular challenge for PCMs is the development of cost functions for forecasting the future value of water stored in reservoirs. The value of stored water as a fuel source for electrical generation depends on several factors that are all time dependent, including the capability and flexibility of stored water to generate electricity, the avoided cost of alternative fuel sources that water is displacing, and the opportunity cost associated with the use of stored water for current rather than future generation. PCMs are solved by minimizing the costs of meeting all electricity demand in a system for a particular period of time. Models such as PCMs have difficulty accounting for the future value of water without external input or additional constraints. Generally, to an optimization problem, the most cost-effective solution is to use all hydropower available in the current time step with no regard to future time steps; however, this is frequently not truly optimal for the entire simulation period. For example, if more water is used for the current operation, the cost of operation in the current interval is reduced, but the water available for future operation is also reduced. As a consequence of this reduction, the future operation may need to use more thermal generation, increasing the future cost.

Models with short time horizons do not typically model the changing value of water. Thus, the value of future water must be added to the model in some manner, or a longer time horizon is needed as an initial optimization to determine the long-term valuation of water. Note that the construction of the future cost function considers the generation that hydropower can displace throughout time. This cost function may change with time, in particular as the end of a water provision period nears [40]. Importantly, the future cost function approach does not violate any of the constraints placed on hydropower operation; it only represents the value of water within a reservoir for future operational intervals. This future cost function of water can incorporate a variety of future benefits, including the displacement of thermal generation and also flexibility resources for incorporating variable renewable resources such as wind and solar power.

\subsection{Regulatory Constraints}

The biggest challenge related to regulatory constraints and modeling hydropower is data availability. Power purchase agreements and minimum and maximum flow requirements can be included in a model if these are known. Obtaining accurate data for these requirements may be challenging, particularly for proprietary power purchase agreements. Additionally, complex water laws may lead to complicated procedures for allocating water in times of drought or water shortage. These laws are not straightforward and would be difficult to accurately incorporate into a power systems model. If drought conditions become more prevalent, or in the case of extreme singular drought events, water rights issues could lead to changes in the requirements on hydropower facilities. 


\section{Potential Improvements to Hydropower Modeling}

Many potential opportunities exist to better represent hydropower in power system models, including incorporating better data measurements, improving existing representations and constraints for hydropower facilities, and linking power system models to watershed models.

\subsection{Improved Hydrological Data}

Significant concerns for appropriately modeling hydropower constraints include the lack of nonproprietary data, consistent data, or enough data to fully account for the variability of hydrological conditions [38]. The lack of data has led to proxies and approximations, which may not fully capture the abilities and restrictions of hydropower facilities. Better data measurements could also be tailored to the specific services a hydropower facility will be providing.

Table 2 shows three main elements in hydropower systems - reservoirs, electric generators, and rivers and reaches - and the data that are required to adequately represent these. The variables selected allow for directly verifying certain operational constraints (e.g., seasonal reservoir surface elevation or minimum environmental flows). Further, some data allow for improving the forecasting of other relevant variables. For example, a better estimation of reservoir evaporation and seepage can be done by sampling more variables that measure reservoir water balance. An important aspect of data measurements is the constraints they inform and the degree to which these constraints can be modeled more accurately. Although the acquisition of more accurate data enables better representations of what hydropower facilities have historically been able to do, hydropower facilities may be able to operate beyond these historical boundaries.

The timing and precision requirements of these measurements vary based on measurement type and system requirements. In some cases, the additional benefits obtained from very precise measurements with very high temporal and spatial sampling frequencies are not significant, whereas in other areas higher frequency and precision can lead to improvements in accurate modeling. For example, small reservoirs might, in a short time period, see a significant change in water head that could induce spilling or a scarcity condition. On the other hand, fluctuations of inflows on a short timescale may not meaningfully impact the reservoir level in a very large reservoir, and hence it might not be necessary to measure the water head as often.

Additionally, increases in the number of years of data could increase the fidelity of models by providing a wide range of operating conditions. Modeling run-of-river hydropower facilities in particular could be improved by an increase in the number of years of data for these facilities to allow for stochastic modeling of water availability [49] or allow the models to be run for years representing typical, drought, and wet conditions. This in turn would accurately represent the impact of these facilities on the power the system during periods of drought or floods.

Table 2 below provides examples of the constraints that could be better informed through additional data. Note that this table is not exhaustive and only provides some examples of the value of increased data measurements. 
Table 2. Data Used in Constraints

\begin{tabular}{cll} 
Element & Data & Constraints Informed \\
\hline \multirow{3}{*}{ Reservoir } & $\begin{array}{l}\text { Water level (water head, or reservoir volume, } \\
\text { or other equivalent measurement) }\end{array}$ & $\begin{array}{l}\text { Release requirements, flood control, } \\
\text { recreational }\end{array}$ \\
\cline { 2 - 3 } & Water inflow & Environmental flow, operation \\
\cline { 2 - 3 } & Water temperature at different levels & Environmental flow, species impacts \\
\cline { 2 - 3 } & Water spilled & Environmental flow \\
\cline { 2 - 3 } & Water flow & Ramping \\
\hline \multirow{3}{*}{\begin{tabular}{c} 
Generator \\
\cline { 2 - 3 } $\begin{array}{c}\text { Rivers, } \\
\text { Reaches, } \\
\text { etc. }\end{array}$
\end{tabular}} & Ramping capabilities & Operational \\
\cline { 2 - 3 } & Wnternal electric demand (e.g., auxiliary & Operational \\
\cline { 2 - 3 } & Wervices, pumps) & Operational \\
\cline { 2 - 3 } & Water level & Release requirements \\
\cline { 2 - 3 } & Wotal dissolved gases & $\begin{array}{l}\text { Species impacts, run-of-river } \\
\text { generation }\end{array}$ \\
\hline
\end{tabular}

\subsection{Improved Representation}

Current representations of hydropower facilities could be improved in several ways to more accurately represent the abilities of these facilities. These improvements may not fully account for all constraints on hydropower facilities, but they would help to improve the models and better approximate all constraints without drastically increasing run times.

Run-of-river hydropower facilities and other small hydropower resources with little or no storage are typically modeled as variable generation, which may not alter their dispatch and can provide energy only when the fuel source is available [49]. Although this is mostly true of run-of-river hydropower, some flexibility exists among these resources, particularly those with a small amount of storage. This storage may not be enough to fully modulate output, but it could add flexibility to the system by slightly shifting generation to better match peaks in demand or to aid in the regulation of variable generation on timescales of several minutes. Additionally, run-ofriver facilities downstream of larger hydropower facilities may be impacted by the outputs of those facilities. This could be accounted for when optimally dispatching larger facilities [39] and when modeling run-of-river facilities.

Ramping constraints can restrict the flexibility of hydropower facilities. This is demonstrated by Harpman [50] in his analysis of the economic costs of environmental constraints on hydropower operations at Glen Canyon Dam. In general, however, hydropower generators have very high ramping capabilities and can change their output rapidly. To more accurately represent the flexibility of the system, ramping constraints from environmental concerns could be modulated throughout the year to represent the changing restrictions on hydropower facilities, allowing them greater flexibility during times with fewer environmental considerations. Additionally, 
increased data could be used to better inform the ramping constraints on individual facilities instead of using averaged ramping requirements for all hydropower generators on a river system.

Another potential improvement from current power system models includes changing environmental issues from being constraints to being objectives of the model [43]. Currently, most models optimize the cost of the system operation. As discussed above, environmental constraints do not have direct costs in the same way power provision does. Optimizing the system to reduce environmental harm and minimize costs would allow for environmental considerations to be more directly addressed; however, this would also increase the complexity and run time of the model. This is also not always possible in proprietary software packages.

The true flexibility of the system could be better represented in the models themselves. Historical data can be used to identify the ability of a hydropower facility to change its output to match load, a proxy for the flexibility of the facility, as demonstrated by Dennis et al. [48]. This study utilizes two methods to represent generator flexibility: (1) a factor representing the ability of a hydropower facility to load follow and modulate output and (2) a factor representing the fraction of the facility's capacity that can respond to price signals instead of being a fixed output. The use of historical data to calculate these flexibility factors implicitly accounts for the hydropower facility's environmental constraints because these constraints will have been met during the historic period from which the data are taken. These values can vary both by time of year and by facility to allow for highly specified representations of the facilities' capabilities.

An additional improvement in the model representation includes improvements to the optimization techniques used. The optimization of hydropower reservoirs can be computationally intensive. Dynamic dual programming allows decomposing multistage optimization problems in a computationally efficient way. This was introduced by Pereira and Pinto [51], and it has been widely used in the industry. This uses a Bender's decomposition approach to construct the future cost function by the intersection of feasibility cuts. Additional improvements to the model representation of flexibility could include finer temporal resolution, which would capture more of the value and flexibility of hydropower for grid operations, particularly as penetration levels of renewable generation increase and variable generation fluctuations represent a higher fraction of available capacity.

\subsection{Link Power System Model and Water System Model}

Linking watershed models with power systems models can provide additional information for both models, allowing the strengths of each model to benefit the other. Two approaches can be used to combine a watershed model and a PCM: (1) an iterative approach, wherein the two tools operate independently of one another but outputs from one are part of the input set for the other; and (2) a combined approach, wherein aspects of a watershed model and PCM are combined in a single integrated tool. The simplest to implement is the iterative approach; however, this may be less accurate than an integrated tool designed explicitly for this purpose.

Given that mature software packages are available to separately model electric systems and water systems, it seems natural to use the output of one as the input to the other and repeat this interaction iteratively. Such an approach is proposed by Ibanez [17], wherein the Western Interconnection grid is represented in PLEXOS, and 10 large reservoirs on the Columbia River are represented using RiverWare. The advantage of this approach is that it reflects the impacts of 
changes from one system on the other. Moreover, it saves time from trying to implement in great detail each system in a new software tool; however, operating two tools for a single study has the disadvantages of being time-consuming and awkward. The iterative approach proposed by Ibanez [17] requires obtaining an offer curve for the electric system for different generation levels, which may be a time-consuming task when several basins and hydropower plants are involved. A second issue concerns the regulation capacity of the reservoir throughout several months. Under that circumstance, the use of water in the present impacts system costs in the future, and therefore the paper's approach might induce incorrect price signals to the watershed model. Third, this approach is not practical to deal with the uncertainty in the water inflows for long-term operation.

Another option includes representing both the water and electrical systems in a single software package, effectively linking the operations of both types of models. The main advantage of this approach is the capability to assess the impact of one system on the other. The drawbacks of this approach come from its implementation, acceptance by stakeholders, and time execution. Moreover, it would likely still require making some assumptions about the implementation of certain constraints to create a tractable optimization problem. There are some potential methods that can be used in the integrated approach (such as stochastic dual dynamic programming) that can overcome the time-consumption issues of the sequential method; however, as the scale of the water system increases, the execution time may be prohibitive for practical applications. 


\section{Conclusions}

Hydropower facilities are complex because of their interconnectedness to both the electric power system and the water system. These systems impose numerous constraints on the operation of hydropower facilities, including environmental constraints (those imposed to limit negative impacts on the environment), operational constraints (the limitation of the generation equipment), and regulatory constraints (binding obligations to contracted purchasers or the grid).

Current power system models often do not fully account for the many constraints faced by hydropower facilities, and therefore they often inaccurately represent the ability of these facilities to respond to an increasing need for system flexibility. As penetration levels of solar and wind continue to increase, power system flexibility will become increasingly important, creating a rising need to better understand the true capabilities of the hydropower generation fleet. Understanding and accurately modeling the limitations and capabilities of hydropower, currently one of the most flexible generators, will enable better preparations for the future integration of variable energy sources.

This study has reviewed many of the constraints facing hydropower facilities and the challenges of accurately modeling these constraints and found that there are several ways in which hydropower can be more accurately modeled, including by collecting more accurate and granular data, improving the representation of constraints within PCMs and CEMs, and linking these models with watershed models to comprehensively account for all constraints associated with the power and water systems. Although some of the proposed solutions would lead to significant increases in model run time, this might be deemed a reasonable trade-off for a higher degree of accuracy. This trade-off should be considered for any modeling exercises that evaluate hydropower facilities within the power system and their ability to provide flexible services to that system. 


\section{References}

1. C. Lins, L.E. Williamson, S. Leitner, and S. Teske, Ten Years of Renewable Energy

Progress: The First Decade: 2004-2014 (Technical Report) (Paris, France: Renewable Energy Policy Network for the 21st Century, 2015),

http://www.ren21.net/Portals/0/documents/activities/Topical\%20Reports/REN21_10yr.pdf.

2. S. Henbest, E. Giannakopoulou, and V. Cuming, "New Energy Outlook 2015," Bloomberg New Energy Finance (June 2015).

3. A. Bloom, A. Townsend, D. Palchek, J. Novacheck, J. King, C. Barrows, E. Ibanez, M. O'Connell, G. Jordan, B. Roberts, C. Draxl, and K. Gruchalla, Eastern Renewable Generation Integration Study (Technical Report NREL/TP-6A20-64472) (Golden, CO: National Renewable Energy Laboratory, 2016), http://www.nrel.gov/docs/fy16osti/64472.pdf.

4. Southwest Power Pool, 2016 Wind Integration Study (Technical Report) (Little Rock, AK: 2016).

5. S. Lu, N. Samaan, D. Meng, F. Chassin, Y. Zhang, B. Vyakaranam et al., Duke Energy Photovoltaic Integration Study: Carolinas Service Areas (Technical Report PNNL-23226) (Richland, WA: Pacific Northwest National Laboratory, 2014), http://www.pnnl.gov/main/publications/external/technical_reports/PNNL-23226.pdf.

6. Transpower stromübertragungs gmbh, European Wind Integration Study (Technical Report TREN/07/FP6EN/S07.70123/038509) (Brussels, Belgium: 2010).

7. GE Energy, PJM Renewable Integration Study (Technical Report) (Schenectady, NY: 2013), http://www.pjm.com/committees-and-groups/subcommittees/irs/pris.aspx.

8. P.D. Lund, J. Lindgren, J. Mikkola, and J. Salpakari,"Review of Energy System Flexibility Measures to Enable High Levels of Variable Renewable Electricity," Renewable and Sustainable Energy Reviews 45 (May 2015): 785-807.

9. P. Denholm and M. Hand, "Grid Flexibility and Storage Required to Achieve Very High Penetration of Variable Renewable Electricity," Energy Policy 39:3 (March 2011):1817-30.

10. J. Cochran, M. Miller, O. Zinaman, M. Milligan, D. Arent, B. Palmintier et al., Flexibility in 21st Century Power Systems. 21st Century Power Partnership (Technical Report NREL/TP-6A20-61721) (Golden, CO: National Renewable Energy Laboratory, 2014).

11. I. Yüksel, "Hydropower for Sustainable Water and Energy Development," Renewable and Sustainable Energy Reviews 14:1 (Jan. 2010):462-9.

12. E.D. Castronuovo and J.A.P. Lopes, "Optimal Operation and Hydro Storage Sizing of a Wind-Hydro Power Plant," International Journal of Electrical Power and Energy Systems 26:10 (Dec. 2004):771-8. 
13. P.D. Brown, J.A.P. Lopes, and M.A. Matos, "Optimization of Pumped Storage Capacity in an Isolated Power System with Large Renewable Penetration," IEEE Transactions on Power Systems 23:2 (May 2008):523-31.

14. M. Kapsali and J.K. Kaldellis, "Combining Hydro and Variable Wind Power Generation by Means of Pumped-Storage under Economically Viable Terms," Applied Energy 87:11 (Nov. 2010): 3475-85.

15. A.R. Ferreira and R.S.V. Teegavarapu, "Optimal and Adaptive Operation of a Hydropower System with Unit Commitment and Water Quality Constraints," Water Resource Management 26:3 (Nov. 2011):707-32.

16. S.J. Pereira-Cardenal, "Water-Energy Modelling: Adaptation to Water Scarcity," Nature Energy 1:2 (Feb. 2016):16004.

17. E. Ibanez, T. Magee, M. Clement, G. Brinkman, M. Milligan, and E. Zagona, "Enhancing Hydropower Modeling in Variable Generation Integration Studies," Energy 74 (Sept. 2014): 518-28.

18. B. Lehner, G. Czisch, and S. Vassolo, "The Impact of Global Change on the Hydropower Potential of Europe: A Model-Based Analysis," Energy Policy 33:7 (May 2005) May: 839_ 55.

19. L. Gaudard and F. Romerio, "The Future of Hydropower in Europe: Interconnecting Climate, Markets and Policies," Environmental Science and Policy 37 (March 2014): 17281.

20. M.T.H. van Vliet, J.R. Yearsley, F. Ludwig, S. Vögele, D.P. Lettenmaier, and P. Kabat, "Vulnerability of U.S. and European Electricity Supply to Climate Change," Nature Climate Change 2:9 (Sept. 2012):676-81.

21. "International Energy Statistics: Electricity," U.S. Energy Information Administration, accessed March 15, 2016, http://www.eia.gov/cfapps/ipdbproject/IEDIndex3.cfm?tid=2\&pid=2\&aid=12.

22. M.J. Nadeau and Y.D. Kim, World Energy Resources Charting the Upsurge in Hydropower Development (Technical Report) (London: World Energy Council, 2015), https://www.worldenergy.org/wp-content/uploads/2015/05/World-EnergyResources_Charting-the-Upsurge-in-Hydropower-Development_2015_Report2.pdf.

23. A. Bartle, "Hydropower Potential and Development Activities," Energy Policy 30:14 (Nov. 2002):1231-9.

24. S. Kao, R. McManamay, K. Stewart, N. Samu, B. Hadjerioua, S. DeNeale et al., New Stream-reach Development: A Comprehensive Assessment of Hydropower Energy Potential in the United States (Technical Report) (Oak Ridge, TN: Oak Ridge National Laboratory, 2014), http://nhaap.ornl.gov/sites/default/files/ORNL_NSD_FY14_Final_Report.pdf. 
25. B. Hadjerioua, Y. Wei, and S. Kao, An Assessment of Energy Potential at Non-Powered Dams in the United States (Technical Report) (Oak Ridge, TN: Oak Ridge National Laboratory, 2012), http://www1.eere.energy.gov/water/pdfs/npd_report.pdf.

26. M. Maupin, J. Kenny, S. Hutson, J. Lovelace, N. Barber, and K. Linsey, Estimated Use of Water in the United States in 2010 (Technical Report Circular 1405) (Reston, VA: U.S. Geological Survey, 2014), http://pubs.usgs.gov/circ/1405/pdf/circ1405.pdf.

27. B. Hamududu and A. Killingtveit, "Assessing Climate Change Impacts on Global Hydropower," Energies 5:2 (2012): 305-22.

28. J.D. Lenters, T.K. Kratz, and C.J. Bowser, "Effects of Climate Variability on Lake Evaporation: Results from a Long-Term Energy Budget Study of Sparkling Lake, Northern Wisconsin (USA)" 308:1-4 (July 2005) Journal of Hydrology:168-95.

29. A.M. Foley, B.P. Ó Gallachóir, J. Hur, R. Baldick, and E.J. McKeogh, "A Strategic Review of Electricity Systems Models," Energy 35:12 (Dec. 2010): 4522-30.

30. "PLEXOS," Energy Examplar, http://energyexemplar.com/software.

31. ABB, "PROMOD IV Technical Overview," 2015, http://new.abb.com/docs/librariesprovider139/default-document-library/promod-ivtechnical-overview_br.pdf?sfvrsn=2.

32. "MAPS," GE Energy, 2013, http://www.geenergyconsulting.com/practice-area/softwareproducts/maps.

33. W. Short, P. Sullivan, T. Mai, M. Mowers, C. Uriarte, N. Blair et al., Regional Energy Deployment System (ReEDS) (Technical Report NREL/TP-6A20-46534) (Golden, CO: National Renewable Energy Laboratory, 2011), http://www.nrel.gov/docs/fy12osti/46534.pdf.

34. T. Mai, E. Drury, K. Eurek, N. Bodington, A. Lopez, and A. Perry, Resource Planning Model: An Integrated Resource Planning and Dispatch Tool for Regional Electric Systems (Technical Report NREL/TP-6A20-56723) (Golden, Colorado: National Renewable Energy Laboratory, 2013). http://www.nrel.gov/docs/fy13osti/56723.pdf.

35. "AURORAxmp," EPIS, Inc., 2016, http://epis.com/aurora_xmp/Auroraxmp.php.

36. E. Zagona, RiverWare, 2013, www.riverware.org.

37. "Water Use Optimization Toolset/Conventional Hydropower Energy and Environmental Systems," Argonne National Laboratory, 2013, http://www.anl.gov/energysystems/project/water-use-optimization-toolsetconventional-hydropower-energy-and.

38. R. Sternberg, "Hydropower's Future, the Environment, and Global Electricity Systems," Renewable and Sustainable Energy Reviews 14 (2010):713-23. 
39. H.I. Jager and M.S. Bevelhimer, "How Run-of-River Operation Affects Hydropower Generation and Value," Environmental Management 40:6 (Sept. 2007):1004-15.

40. B.K. Edwards, S.J. Flaim, and R.E. Howitt, "Optimal Provision of Hydroelectric Power under Environmental and Regulatory Constraints," Land Economics 75:2(1999): 267-83.

41. B.D. Richter and G.A. Thomas, "Restoring Environmental Flows by Modifying Dam Operations," Ecology and Society 12:1(2007): 1-26.

42. J. Carron, E. Zagona, and T. Fulp, "Uncertainty Modeling in RiverWare," in Watershed Management and Operations Management (Fort Collins, CO: American Society of Civil Engineers: 2000 ), 1-11, http://ascelibrary.org/doi/abs/10.1061/40499\%282000\%2958.

43. H.J. Jager and B.T. Smith, "Sustainable Reservoir Operation: Can We Generate Hydropower and Preserve Ecosystem Values?" River Research and Applications 24:3(March 2008): 340-52.

44. N.W. Arnell, "Climate Change and Global Water Resources," Global Environmental Change 9: Supplement 1 (Oct. 1999): S31-49.

45. A.R. Fernandez, S.A. Blumsack, and P.M. Reed, "Operational Constraints and Hydrologic Variability Limit Hydropower in Supporting Wind Integration," Environmental Research Letters 8:2 (2013): 024037.

46. X. Escaler, E. Egusquiza, M. Farhat, F. Avellan, and M. Coussirat, "Detection of Cavitation in Hydraulic Turbines," Mechanical Systems and Signal Processing 20:4 (May 2006): 9831007.

47. D.P. Sheer, "Dysfunctional Water Management: Causes and Solutions," Journal of Water Resources Planning and Management 136:1 (2010):1-4.

48. C.M. Dennis, R.C. Walish, H.M. Pacini, T.A. Chisholm, and T.L. Acker. "Improving Hydrogeneration Representation in a Production Cost Model Used for Long-Term Transmission Studies in the Western Interconnection," Power Systems Conference and Exposition (PSCE) (2011): 1-8.

49. C.L.T. Borges and R.J. Pinto, "Small Hydro Power Plants Energy Availability Modeling for Generation Reliability Evaluation," IEEE Transactions on Power Systems 23:3 (Aug. 2008): 1125-35.

50. D.A. Harpman, "Assessing the Short-Run Economic Cost of Environmental Constraints on Hydropower Operations at Glen Canyon Dam," Land Economics 75:3 (1999):390-401.

51. M.V.F. Pereira, and L.M.V.G. Pinto, "Multi-Stage Stochastic Optimization Applied to Energy Planning," Mathematical Programming 52: 1-3 (May 1991):359-75. 